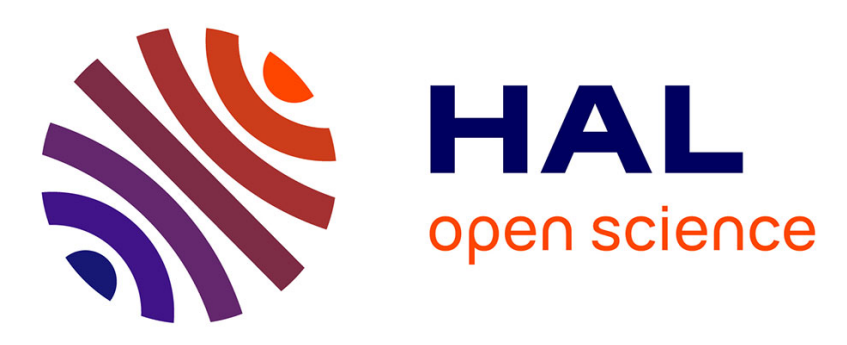

\title{
Selective extraction and separation of germanium by catechol based resins
}

\author{
Carlos Arrambide Cruz, Sébastien Marie, Guilhem Arrachart, S \\ Pellet-Rostaing
}

\section{- To cite this version:}

Carlos Arrambide Cruz, Sébastien Marie, Guilhem Arrachart, S Pellet-Rostaing. Selective extraction and separation of germanium by catechol based resins. Separation and Purification Technology, 2018, 193, pp.214-219. 10.1016/j.seppur.2017.11.013 . hal-02062514

\section{HAL Id: hal-02062514 https://hal.science/hal-02062514}

Submitted on 25 Oct 2021

HAL is a multi-disciplinary open access archive for the deposit and dissemination of scientific research documents, whether they are published or not. The documents may come from teaching and research institutions in France or abroad, or from public or private research centers.
L'archive ouverte pluridisciplinaire HAL, est destinée au dépôt et à la diffusion de documents scientifiques de niveau recherche, publiés ou non, émanant des établissements d'enseignement et de recherche français ou étrangers, des laboratoires publics ou privés. 


\title{
Selective extraction and separation of germanium by catechol based resins
}

\author{
Carlos Arrambide Cruz, Sébastien Marie, Guilhem Arrachart*, Stéphane Pellet-Rostaing \\ ICSM, CEA, CNRS, Univ Montpellier, ENSCM, Bagnols sur Cèze Cedex, France \\ *Corresponding author. E-mail address: guilhem.arrachart@cea.fr
}

\begin{abstract}
Germanium extraction has been studied using ion-exchange process thanks to polymeric resins. The ion-exchange resins have been prepared from catechol and with admixture with 8-hydroxyquinoline by alkaline polycondensation with formaldehyde. The polymeric resins were characterized and involved in sorption experiment. The selectivity sorption of germanium was studied in the presence of elements such as silicon, zinc or copper which are likely to be competitive cations in solutions from urban mines or mine deposits. Selective extraction and separation of germanium have been demonstrated. Changes in the selectivities properties of the resins have been observed through the incorporation of 8-hydroxyquinoline in the catechol matrix.
\end{abstract}

\section{Introduction}

Germanium is a trace component in the Earth's crust and natural waters. It is used as a component of optical fibers, polymerization catalyst, element in infrared optics and electronics, and in many other applications. The wide use of $\mathrm{Ge}$ in the manufacture of electronic makes it an element of high technological value [1]. Germanium is recovered as a by-product of zinc or copper and zinc ores, it is also extracted from some coals deposits [2]. The separation of germanium from acid solutions has received considerable attention because of its economic implications.

Hydrometallurgy appears to be the most attractive process for the recovery of germanium. This includes, the liquid-liquid extraction [3-6], flotation [7,8] and the resin [9-11] separation methods. Polyols are known to form complexes with germanium [12]; therefore polymeric solids containing hydroxy groups, such as N-methylglucamine $[9,13]$ and catechol derivatives [14-17] have been used for the preconcentration and separation of germanium. Catechol forms a negatively charged complex with germanium in solution [17-21] and that complexation with germanium and catechol forms a symmetric structure in three dimensions which is a more stable complex compared with the silicate ion $[15,16]$. In most of the recovery system using catechol, the germanium ion is complexed with catechol in a homogeneous system, and the resulting anionic germanium complex is then captured using an anion-exchange resin or membrane $[15,17]$. The predominant oxidation state of germanium is Ge(IV) however the Ge4+ ion is easily hydrolysed and is rarely existing in aqueous solutions [13]. Indeed, germanium is mainly found in the form of germanic acid, $\mathrm{Ge}(\mathrm{OH}) 4$, and Ge-oxoanions in aqueous solutions. At $\mathrm{pH}$ lower than 4 , germanium predominantly exist in non-complexed form and at higher $\mathrm{pH}$ the formation of a catechol complex is proposed according to Eq. (1)and illustrated in Fig. 1. $[17,21]$

The selectivity of Ge towards $\mathrm{Zn}$ and $\mathrm{Cu}$ is important when considering the Ge recovery from zinc or copper and zinc ores. From the waste from the industry of semiconductor, optical fibers and solar panels, Ge is contained along with large concentration of silicate ion which implies a high selectivity against silicate ion using the hydrometallurgy process. 


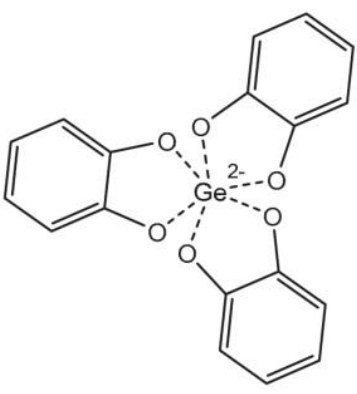

Fig. 1. Schematic structure of the germanium-catechol complex.

In this process, the germanium-containing waste is dissolved into an alkaline or acid solution. The formo-phenolic resins, which result from the alkaline polycondensation of formaldehyde with a phenolic compound, are one of the best known types of chelating polymers [22,23]. The ion-exchange properties are provided by the presence of the phenolic $\mathrm{OH}$ groups, therefore a wide variety of phenolic-formaldehyde polymers that contain a variety of active chelating groups have been reported in the literature and used to sorb various heavy metals [24-26], lanthanide metal ions [27-31] and radionucleides [32-36]. Interestingly, to our knowledge, in the literature there is no example of the use of such resins for the selective extraction of Ge.

Due to the selective complexation of germanium ions with catechol, and the potential of oxine for the extraction of germanium, we decide to explore the possibility to use formo-phenolic resins based on catechol and/or oxine (8-quinolinol/8-hydroxyquinoline) for the separation of Ge from Zn and Si. Also other phenolic precursor such as phenol and resorcinol have been explored.

\section{Experimental}

\subsection{Resins synthesis}

Catechol (C), 8-quinolinol or 8-hydroxyquinoline (Q), phenol (P), resorcinol (R), and formaldehyde (F) ( $37 \%$ aqueous solution) were obtained from Aldrich or Acros and used without further purification. The resins were synthesized by alkaline polycondensation of formaldehyde with phenolic compounds according to procedure adapted from the literature [37,38]. Typically, a phenolic compound/ formaldehyde/ $\mathrm{NaOH} / \mathrm{H}_{2} \mathrm{O}$ molar ratio of 1:2.5:1.5:80 were used with the objective to obtain a resol type resin resulting in insoluble and infusible polymeric materials. The homopolymerization of 8hydroxyquinoline using formaldehyde as a crosslinker in basic conditions gave a large amount of watersoluble materials. To overcome this drawback, the resins were prepared through a polycondensation reaction between 8-hydroxyquinoline and catechol using formaldehyde as crosslinker in the presence of an alkaline hydroxide $(\mathrm{NaOH})$ as a catalyst.

The phenolic or mixture of phenolic precursors $(1 \mathrm{mmol})$ were dissolved in an alkaline hydroxide solution $(1.5 \mathrm{mmol}$ of $\mathrm{NaOH}$ from a $6 \mathrm{M}$ solution). Water is added to reach the amount desired ( 80 $\mathrm{mmol}$ of $\left.\mathrm{H}_{2} \mathrm{O}\right)$. The solution was stirred at room temperature, then the formaldehyde $(2.5 \mathrm{mmol})$ was added using a syringe pump at $20 \mathrm{~mL} / \mathrm{h}$. During formaldehyde addition, the solution was maintained at 0 or $25^{\circ} \mathrm{C}$. After the addition, the mixture was stirred for $24 \mathrm{~h}$ at room temperature. After stirring, the mixture was heated in an oven in air at $100{ }^{\circ} \mathrm{C}$ for $96 \mathrm{~h}$. After curing, the polymers were crushed by ball-milling and submitted to a washing step with $1 \mathrm{M} \mathrm{HCl} / \mathrm{H}_{2} \mathrm{O} / 1 \mathrm{M} \mathrm{NaOH} / \mathrm{H}_{2} \mathrm{O}$ cycles to remove 
the unreacted compounds and the oligomers which have not been well crosslinked. Finally, the resin was dried in air at $80^{\circ} \mathrm{C}$ for $24 \mathrm{~h}$. A list of synthesized resins is summarized in Table 1 and an example of their synthesis is illustrated in Fig. SI-1 (see supporting information).

\subsection{Resin characterization}

The ball-milling was performed on a Retsch mixer mill MM 200 using a Zr ball under strong horizontal stirring at $50 \mathrm{~Hz}$ for $10 \mathrm{~min}$. The statistical study of the size of the particles was carried out using Fiji software from the treatment of optical microscopy images obtained from a Zeiss Axio Imager microscope. From the analysis of images, different treatments can be performed on the particles (thresholding, erosion/dilatation, etc.) to estimate the size and polydispersity of the particles.

FTIR spectra were recorded with a Perkin Elmer 100 spectrometer between 400 and $4000 \mathrm{~cm}^{-1}$ using an ATR crystal with $4 \mathrm{~cm}^{-1}$ resolution.

The ${ }^{13} \mathrm{C}$ solid-state MAS NMR spectra were recorded with a Varian VNMRS 300 solid spectrometer with MAS probe using $3.2 \mathrm{~mm}$ outer diameter rotors with a spinning rate of $12 \mathrm{kHz}$ (typical contact time: 2$3 \mathrm{~ms}$, typical recycle delay: $5 \mathrm{~s}$ ).

Thermal analysis (TGA) was performed with a Mettler Toledo Instrument under air flow with a heating rate of $10^{\circ} \mathrm{C} / \mathrm{min}$ from 25 to $950^{\circ} \mathrm{C}$. The moisture regain was determined from the TGA analysis after an heating after in air from 25 to $100^{\circ} \mathrm{C}$ at $10^{\circ} \mathrm{C} / \mathrm{min}$ followed by an isothermal treatment of $30 \mathrm{~min}$ at $100{ }^{\circ} \mathrm{C}$. The corresponding weight loss giving the percentage of water in the resin (see Table S1 supporting information).

For determination of total ion-exchange capacity, $0.1 \mathrm{~g}$ of resin in the $\mathrm{H}$-form was equilibrated for 24 h with $20 \mathrm{~mL}$ of $0.1 \mathrm{~N} \mathrm{NaOH}$ solution containing $5 \% \mathrm{NaCl}$. The amount of $\mathrm{NaOH}$ consumed in the $\mathrm{H}-\mathrm{Na}$ exchange was determined by titrating the remaining $\mathrm{NaOH}$ in the supernatant with $0.1 \mathrm{M} \mathrm{HCl}$ solution. Assuming a complete crosslinking and if all the $\mathrm{OH}$ groups are accessible in the polymer, the theoretical expected $\mathrm{H}-\mathrm{Na}$ ion-exchange capacity of the polymer would be $8.9 \mathrm{meq} / \mathrm{g}$ and $15.6 \mathrm{meq} / \mathrm{g}$ for a hydroxybenzene and dihydroxybenzene resin respectively [37]. For the various resins around $50 \%$ of the phenolic group can undergo ion-exchange process. The ion-exchange capacities are summarized in Table S1 (see supporting information) and are close to those obtained in the literature for such resins [28].

Elemental analysis (Fig. SI-2 see supporting information) were carried out with an Elementar Vario Micro Cube instrument. The morphology of the resins was observed using an environmental scanning electron microscope (model FEI QUANTA 200 ESEM FEG). XEDS analyses were performed using a Bruker AXS X-Flash 5010 detector coupled with SEM to quantitatively determine the elementary atomic percentages.

Quantification of cation concentration in solution was conducted by inductively coupled plasma/atomic emission spectroscopy (ICP/AES) using a SPECTRO ARCOS spectrometer. The wavelengths for the measurements for the Ge $(164.919,206.866,209.426,219.871$ and $265.118 \mathrm{~nm})$, $\mathrm{Zn}(202.613,213.856$ and $334.502 \mathrm{~nm})$, Si $(152.672,251.612$ and $288.158 \mathrm{~nm})$ and $\mathrm{Cu}(224.700$, 324.754 and $327.396 \mathrm{~nm}$ ) were chosen to avoid any spectral interference between the elements.

\subsection{Batch contact with cation solutions}

The metallic solutions were obtained after dilution with Milli- $\mathrm{Q}^{\circledR}$ water of from $1000 \mathrm{mg} / \mathrm{L}$ of ICP standard (in 1\% HNO3) of germanium (Ge), and /or silicon ( $\mathrm{Si})$, zinc ( $\mathrm{Zn}$ ), and copper ( $\mathrm{Cu}$ ). For all solutions, the $\mathrm{pH}$ was measured by a pH meter (Metrohm $780 \mathrm{pH}$ Meter) and found to be 
approximately 6 . The concentrations were initially set at $10 \mathrm{ppm}$ of $\mathrm{Ge}, \mathrm{Si}$ and $\mathrm{Zn}$ in an attempt to avoid saturation of the functional sites.

Other experiments were conducted with a ten-fold higher concentration of competitors metals with respect to germanium: (i) 10 ppm of Ge with 100 ppm of Si; (ii) 10 ppm of Ge with 100 ppm of Zn; (iii) $10 \mathrm{ppm}$ of Ge with $100 \mathrm{ppm}$ of $\mathrm{Zn}$ and $100 \mathrm{ppm}$ of $\mathrm{Cu}$. The choice of concentrations was chosen to best represent the characteristic values of the effluents as well as allow their characterization through the ICP analyses after the extractions experiments. Even if the concentrations are not representative of those encountered in the mineral deposits, they make it possible to give trends on the extraction and selectivity performances in the context of germanium recovery.

Batch contacts were generally run for $24 \mathrm{~h}$. The mixtures were shaken (rotary mixer speed rate: 1 rotation/s). The solution to solid ratio was typically $1000(1 \mathrm{~g} / \mathrm{L})$, although it was varied from 400 (2.5 $\mathrm{g} / \mathrm{L})$ to $100(10 \mathrm{~g} / \mathrm{L})$ in certain experiments to determine the effect on the extraction efficiencies. After shaking the mixture for the specified time, they were filtered through a $0.2 \mu \mathrm{m}$ filter and analysed by ICP to determine the residual metal concentration.

The distribution coefficient $\mathrm{Kd}(\mathrm{mL} / \mathrm{g}$ ) was calculated using the following Eq. (1) in which $\mathrm{Ci}$ is the initial concentration of the metal ion in solution, $\mathrm{Cf}$ is the residual metal ion concentration, and $\mathrm{V} / \mathrm{m}$ is the solution volume to solid-mass ratio ( $\mathrm{V}=$ volume of the treated solution and $\mathrm{m}=$ mass of the resin used): $\mathrm{Kd}=((\mathrm{Ci}-\mathrm{Cf}) / \mathrm{Ci}) \times \mathrm{V} / \mathrm{m}$.

The adsorption efficiency $\mathrm{E}(\%)$ was calculated according to the equation $\mathrm{E}=((\mathrm{Ci}-\mathrm{Cf}) / \mathrm{Ci}) \times 100$.

The separation factor $\mathrm{SF} G / \mathrm{M}$ was determined according to the equation $\mathrm{SF} G e / M=\mathrm{E}_{\mathrm{Ge}} / \mathrm{E}_{\mathrm{M}}$.

Kinetics experiments were run in the same fashion as for the batch contacts, except that aliquots were removed at specified time intervals, filtered through a $0.2 \mu \mathrm{m}$ filter, and subjected to ICP analysis. Kinetics experiments revealed that equilibrium was achieved in 1-3 $h$, indicating all experimental results represent true equilibrium conditions.

\section{Results and discussion}

\subsection{Resin synthesis and characterizations}

The influence of the preparation of polymers bearing various phenolic compounds as monomers was preliminary studied. Resol resins type were prepared using an excess of formaldehyde compared to the phenolic compound in basic conditions. The molar ratio was considered to obtain solubilisation of the mixture before the addition of formaldehyde and adjusted from previous synthesis of formophenolic resins [32]. The co-polymerisation results in an uncontrolled crosslinking through a methylene linkage between the phenolic precursors. Following this procedure various resins were synthesized by varying the nature of the phenolic precursors (Table 1 ).

After conditioning of the insoluble resins (three cycles $1 \mathrm{M} \mathrm{HCl} / \mathrm{H}_{2} \mathrm{O} / 1 \mathrm{M} \mathrm{NaOH} / \mathrm{H}_{2} \mathrm{O}$ ), we noticed a decrease in the mass which can be attributed to an elimination of the partially soluble oligomeric species. We measured the highest percent loss of mass resin when 8-hydroxyquinoline was used whether during the homopolymerization or heteropolymerization with $25 \%$ of catechol with respectively $70 \%$ of loss in comparison to the values obtained for the other one that are around 35$40 \%$. The homopolymerization of 8-hydroxyquinoline using formaldehyde as crosslinker in basic conditions gave a large amount of water-soluble materials which are not applicable in solid-liquid extraction. This is due to the fact that the 8-hydroxyquinoline have two reactive sites (an ortho- and a para- position on its phenol ring) which are difficult to polymerize. 
Table 1 List of polymeric resins synthesized by alkaline polycondensation of formaldehyde and phenolic derivatives: Catechol (C), 8hydroxyQuinoline (Q), Phenol (P) and Resorcinol (R).

\begin{tabular}{ll}
\hline Polymer & Composition \\
\hline I & $100 \% \mathrm{C}$ \\
II & $75 \% \mathrm{C}-25 \% \mathrm{Q}$ \\
III & $50 \% \mathrm{C}-50 \% \mathrm{Q}$ \\
IV & $25 \% \mathrm{C}-75 \% \mathrm{Q}$ \\
V & $100 \% \mathrm{Q}$ \\
VI & $100 \% \mathrm{P}$ \\
VII & $100 \% \mathrm{R}$ \\
\hline
\end{tabular}

To overcome this drawback, the resins were prepared by polycondensation reaction between the 8hydroxyquinoline and catechol using formaldehyde as crosslinker in the presence of alkaline hydroxide as catalyst $(\mathrm{NaOH})$. After the washing step infusible, insoluble, amorphous, crosslinked polymer are obtained which are applicable in solid-liquid extraction.

Each resins were crushed thanks to a ball-milling treatment. The ball-milling of the polymers allows the reduction of the particle size from $500 \mu \mathrm{m}$ to sizes smaller than $100 \mu \mathrm{m}$ with mainly particles size about $10 \mu \mathrm{m}$ (Fig. SI-3 see supporting information). This treatment makes it possible to reduce the size of the particles which is conventionally included between $250-850 \mu \mathrm{m}$ for ion-exchanger material and allow to increase the surface contact area of these resins. The crushed resins were examined using SEM and showed particles with smooth glass-like surfaces that lack pore structure (Fig. SI-4 see supporting information). Scratches on the surface shows a rough surface inside the particles which may be due to a local swelling.

The typical structure of the polymers is depicted with the IR spectra of the polymers I-V in Fig. SI-5 (see supporting information). We observed the characteristics band of the precursors such as the broad band at $3300 \mathrm{~cm}^{-1}$ indicative of $\mathrm{O}-\mathrm{H}$ bond stretching from the ring hydroxyls. The band at 2985 and $2900 \mathrm{~cm}^{-1}$ arise from the $\mathrm{C}-\mathrm{H}$ stretching of the methylene linkages between the phenolic rings and the ring skeletal vibrations appears at around 1600,1460 and at $815 \mathrm{~cm}^{-1}$ with the aromatic C-H out-ofplane deformation band which is indicative of the ring substitution pattern. Characteristic signature of the 8-hydroxyquinoline is observed at 1500 and at $780 \mathrm{~cm}^{-1}$, this two band increase with the increase of 8-hydroxyquinoline ratio in the polymeric resin. The $3500-3000 \mathrm{~cm}^{-1}$ region appear to be different in the resin $\mathrm{V}$, this difference can be attributed to the hydroxy groups of 8-hydroxyquinoline intramolecularly hydrogen bonded to the nitrogen and maybe the presence of methylol hydroxyl group. Also, the different bands of this polymeric resin (V) are narrower reflecting the fact that the resin is less well crosslinked than the one with a catechol matrix.

Elemental analysis for the resins R1 to R5 were carried out and the progressive increase in the nitrogen content from 0 to $8 \%$ with the increase in the percentage of 8 -hydroxyquinoline suggest the incorporation of this group into the polymer matrix (Fig. SI-2). This result has been correlated with ${ }^{13} \mathrm{C}$ MAS solid state NMR with the typical displacement of the aromatic carbons at $125 \mathrm{ppm}$ and phenolic carbons at $145 \mathrm{ppm}$ and bridging methylene carbons at around $30 \mathrm{ppm}$ (Fig. 2). As illustrated in the Fig. 2, the introduction of 8-hydroxyquinoline in the catechol resin (III) slightly modifies the characteristic region of aromatic carbons with a displacement around $148 \mathrm{ppm}$ for the phenolic carbons and the apparition of a shoulder around $138 \mathrm{ppm}$ characteristic of aromatic carbons of the 8hydroxyquinoline. 


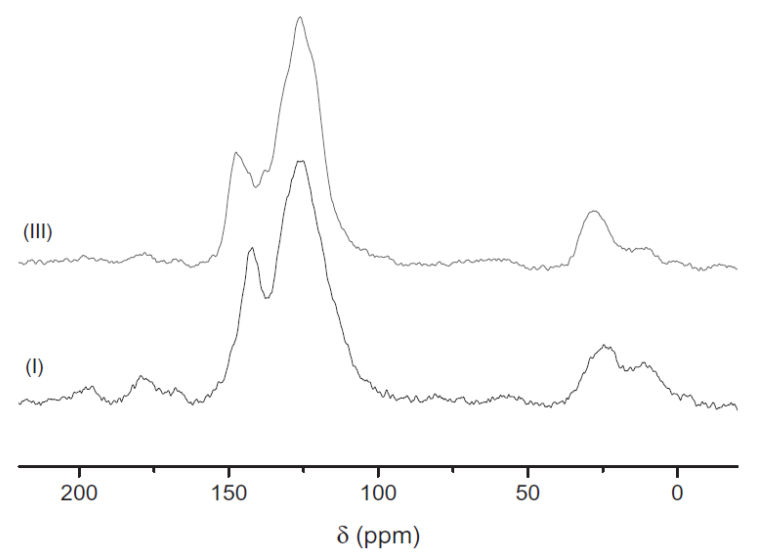

Fig. $2 .{ }^{13} \mathrm{C}$ solid state NMR spectra of Polymers I and III.

The moisture regain was determined from the thermogravimetric analysis after a heating after in air at $100{ }^{\circ} \mathrm{C}$. The weight loss corresponding to the percentage of water in the resin are summarized in Table SI-1 (see supporting information). A moisture content of about $10 \%$ was estimated for the various polymers which is in agreement with the values obtained for such resins [28]. To facilitate comparison between the thermograms, they are plotted after the heat treatment allowing the evaluation of the moisture regain. The thermogravimetry curves along with the derivative thermogravimetry (DTG) curves of two resins are shown in Fig. 3a and b for the resin I and III, respectively. Thermal analysis shows clearly the mass loss of both polymers by air flow which indicate different behaviour with one stage decomposition for polymer I and two stages decomposition for polymer III (Fig. 3a). The thermal degradation takes place over a wide temperature range and finally both resins were completely degraded resulting from their thermooxidation. Derivative thermogravimetry curves (Fig. $3 \mathrm{~b}$ ) shows a mass reduction through one endothermic peak at $500{ }^{\circ} \mathrm{C}$ for polymer $\mathrm{I}$ and two endothermic peaks at around $500^{\circ} \mathrm{C}$ and $600{ }^{\circ} \mathrm{C}$ for polymer III. The degradation process of the catechol resin I is mainly obtained in one stage while for the resin III incorporating the 8-hydroxyquinoline in the polymer matrix the degradation process can be divided into two stages. It appears that the decomposition takes place over a wide temperature range with endothermic peak centred at 500 and $600{ }^{\circ} \mathrm{C}$ corresponding to the catechol and 8- hydroxyquinoline pattern of the resin respectively.
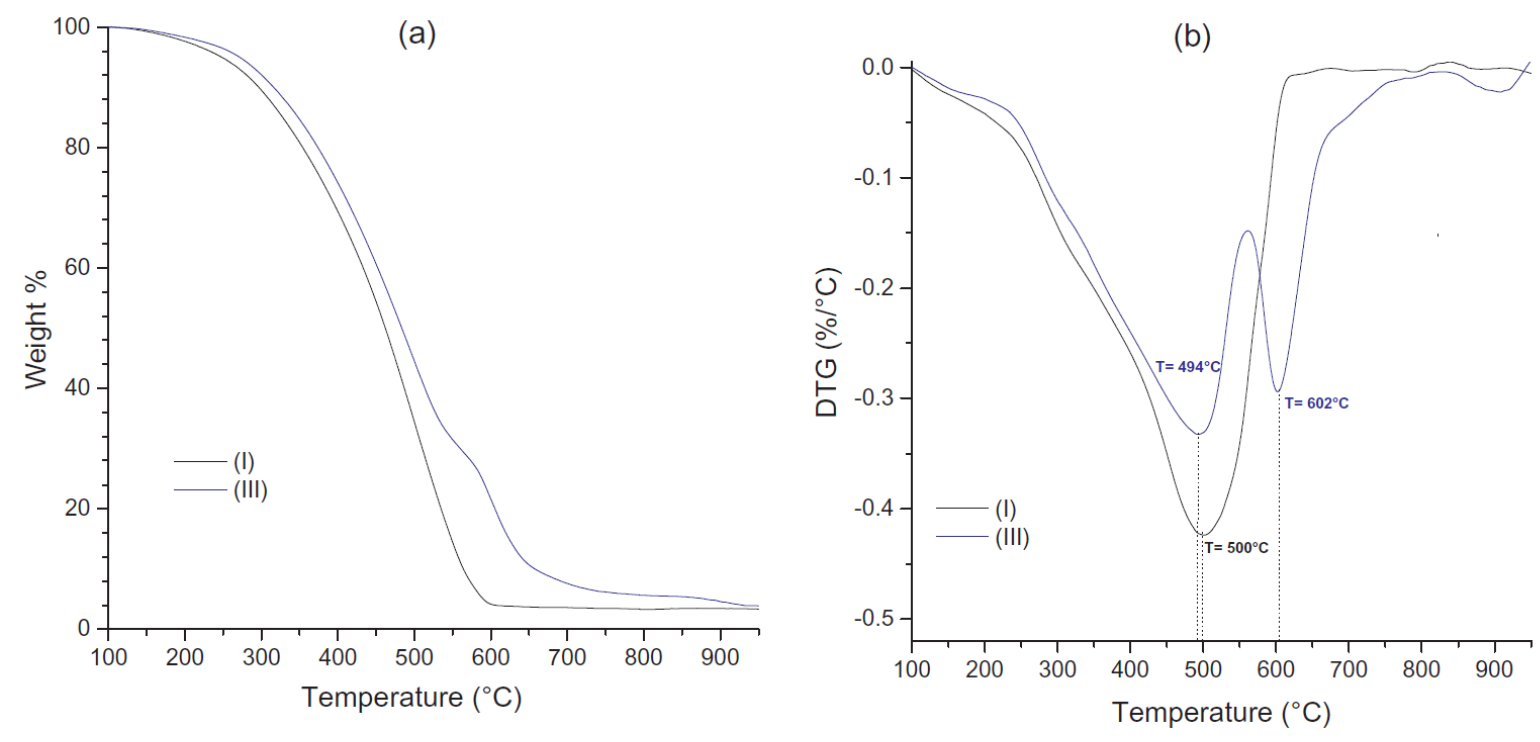

Fig. 3. Thermal analysis data of the resins I and III: (a) TG and (b) DTG curves at $10^{\circ} \mathrm{C} / \mathrm{min}$ under an air atmosphere. 


\subsection{Batch contact with cation solutions}

The $\mathrm{pH}$ is an important parameter affecting the affinity of a resin for a particular ion and also affecting the germanium-catechol chelate formation, a pH of 6 was considered in our study since it has been shown that germanium is poorly extracted at $\mathrm{pH}<4$ and $\mathrm{pH}>9[17,21]$. The distribution coefficient $(\mathrm{Kd})$ and adsorption efficiency (E) for each cation were calculated after submersing the resins in different aqueous solutions for $24 \mathrm{~h}$. Kinetics experiments (Fig. Sl-6 see supporting information) revealed that equilibrium was achieved in only $1-3 \mathrm{~h}$, confirming the systems were in true equilibrium. Inductively coupled plasma (ICP) was used to determine the initial and residual metal concentrations.

Preliminary screening tests were performed to evaluate the efficiency of the resins towards the extraction of $\mathrm{Ge}, \mathrm{Si}, \mathrm{Zn}$. The suitability of the resin is associated with an extraction efficiency value which is as high as possible and with the highest possible separation factor SF Ge/M with M=Si or Zn. The first experiments were conducted with $1 \mathrm{~g} / \mathrm{L}(10 \mathrm{mg}$ in $10 \mathrm{~mL} ; \mathrm{V} / \mathrm{m}=1000)$ of resin I, II and III, the resin was submersed in pure water doped with $10 \mathrm{ppm}$ of each metals $(\mathrm{pH} 6)$. The results illustrated in Fig. 4 indicate that the Ge is preferably extract in comparison to $\mathrm{Zn}$ and Si. After extraction, the presence of germanium in the resins has been highlighted through X-EDS analyses (Fig. SI-7, see supporting information). The catechol resin (polymer I) is able to selectively extract the Ge towards $\mathrm{Si}$ with separating factor $\mathrm{SF} \mathrm{Ge/Si} \mathrm{of} \mathrm{28,} \mathrm{when} \mathrm{8-hydroxyquinoline} \mathrm{is} \mathrm{introduced,} \mathrm{such} \mathrm{as} \mathrm{in} \mathrm{the} \mathrm{resin} \mathrm{II}$ (25\%) and resin III (50\%), the extraction of $\mathrm{Si}$ is increased and therefore the SF Ge/Si decrease up to 1.6. An interesting point is that the introduction of the 8-hydroxyquinoline makes it possible to have a more pronounced selectivity towards Zn which reaches a SF Ge/Zn of 16 . It appear that the selective separation of Ge towards Si and Ge towards $\mathrm{Zn}$ can be proceed thanks to the catechol resin (resin I) and catechol resin with 8-hydroxyquinoline (resin II and III) respectively.

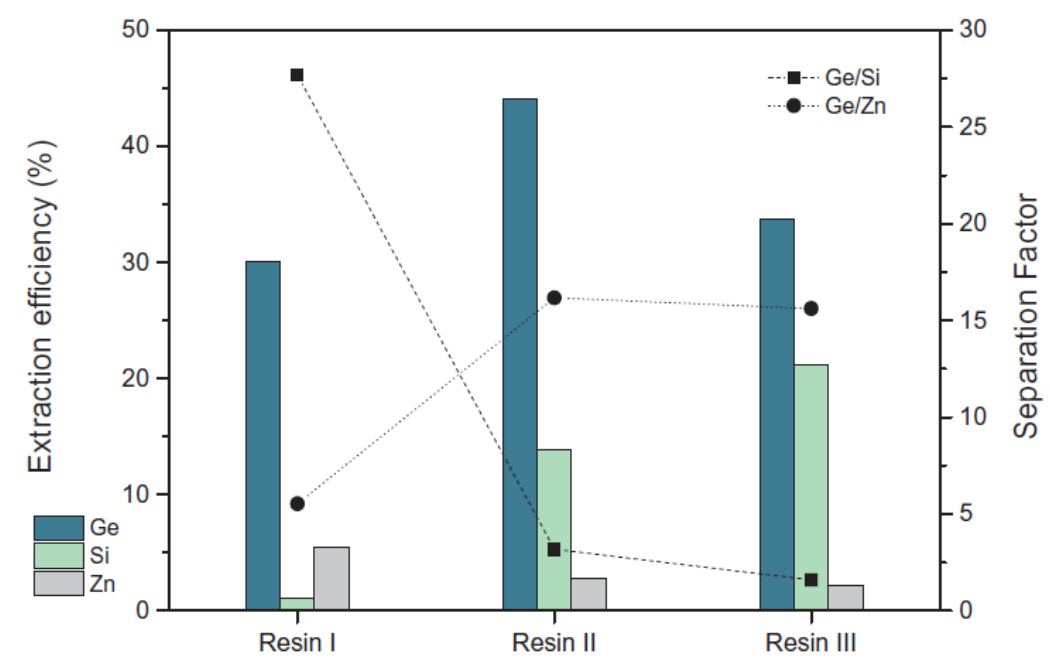

Fig. 4. Extraction of $\mathrm{Ge}, \mathrm{Si}$ and $\mathrm{Zn}$ by resin I, II or III (at $1 \mathrm{~g} / \mathrm{L}$ ) from mixed cation solutions with each cation at nominal $10 \mathrm{mg} / \mathrm{L}$ ( $\mathrm{pH}=6$ ). The $\mathrm{V} / \mathrm{m}$ ratio was 1000 .

By increasing the amount of resins (Fig. 5) the efficiency was increased with the possibility to quantitatively extract the germanium with separation factors SF Ge/Si higher than 100 using a concentration of $10 \mathrm{~g} / \mathrm{L}$ of resin I and a SF Ge/Zn higher than 20 using a concentration of $10 \mathrm{~g} / \mathrm{L}$ of resin III (distributions coefficients Kd are illustrated in Fig. SI-8 see supporting information). It appear that the best compromise for the separation of germanium towards zinc is the use of the resin II or III with a concentration of $2.5 \mathrm{~g} / \mathrm{L}$ allowing a SF Ge/Zn higher than 80 . 

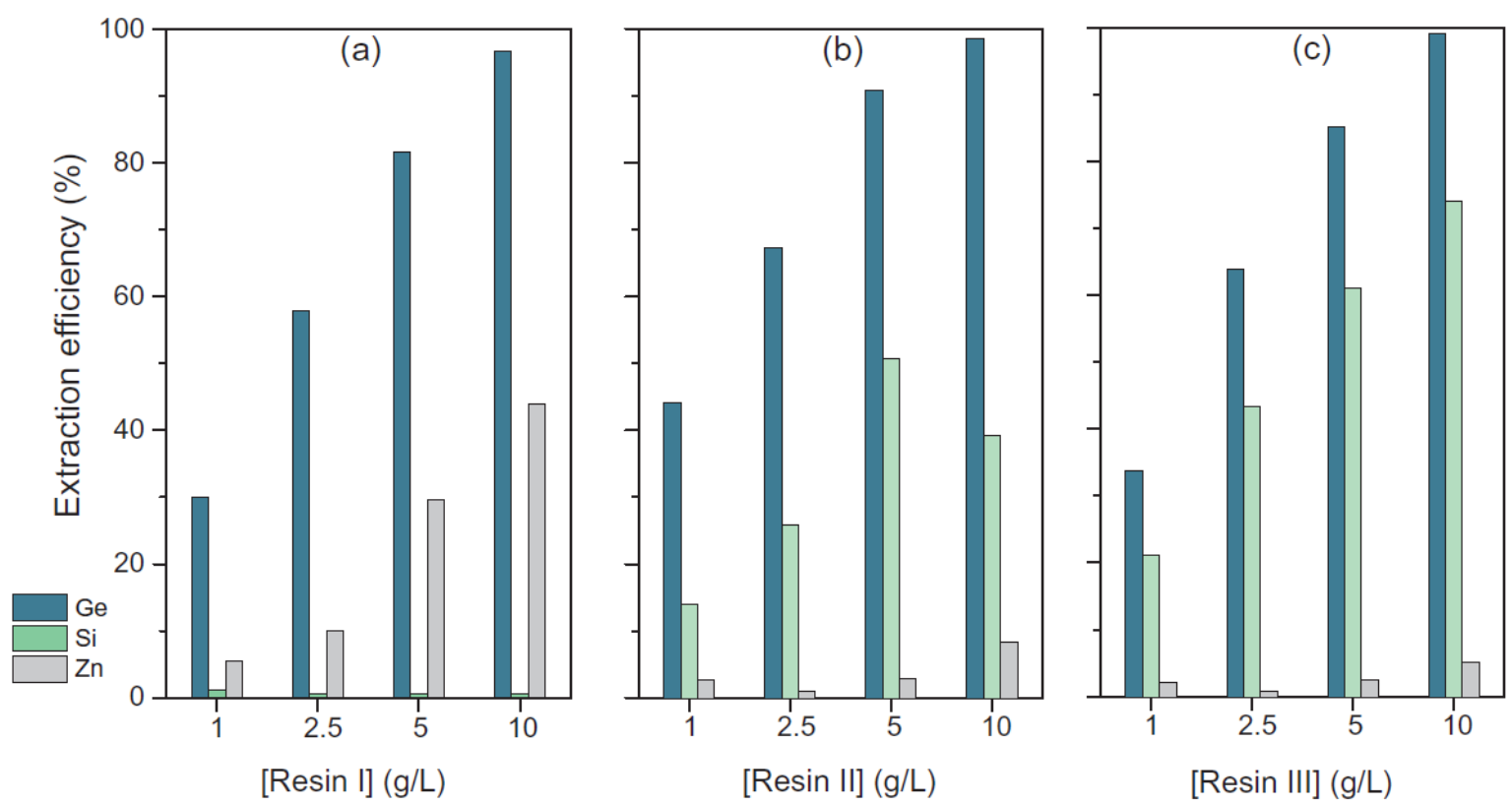

Fig. 5. Extraction of Ge, Si and Zn by resin (a) I, (b) II or (c) III at various concentration (1-10 g/L) from mixed cation solutions with each cation at nominal $10 \mathrm{mg} / \mathrm{L}(\mathrm{pH}=6)$.

A relevant comparison with similar or close sorption experiment is difficult. Indeed, sorption properties depends mainly on the nature of the ion-exchanger used and on the nature of the solution used. In a previous work, the selectivity of germanium ion against silicate ion was determined of approximately 15 for germanium extraction using a process based on a catechol complexation and permeation through an anion-exchange membrane with an initial Ge and Si concentration of 58 and $188 \mathrm{ppm}$ respectively [15]. Similarly, Torralvo et al. described the sorption of the catechol - germanium complex onto anionic resins with a Ge/Zn selectivity of about 125 with an initial Ge and $\mathrm{Zn}$ concentration of 36 and $2 \mathrm{ppm}$ respectively $[17,19]$. Therefore, compared with the literature, this work obtained competitive selectivity values with respect to the extraction condition studied. From the preliminary extraction experiments it could be identified that the resins likely to have the best performance for the separation $\mathrm{Ge} / \mathrm{Si}$ are the resins containing only a catechol group (resin I) while introduction of with 8-hydroxyquinoline (resin II and III) allow the separation Ge/Zn.

A second set of experiments have been performed with two different aqueous solutions: i) a mixture of $100 \mathrm{ppm}$ of Si and $10 \mathrm{ppm}$ of Ge for the resin I or ii) a mixture of $100 \mathrm{ppm}$ of $\mathrm{Zn}$ and $10 \mathrm{ppm}$ of Ge with or without $\mathrm{Cu}(100 \mathrm{ppm})$ for the resin III, in order to investigate the extraction of the Ge with respect to higher concentration of $\mathrm{Si}$ or $\mathrm{Zn}$ and $\mathrm{Cu}$. The results confirm the previously observed tendencies even with a 10 times greater amount of competitors ( $\mathrm{Si}$ or $\mathrm{Zn}$ ) than Ge. No extraction of Si by the resin I or Zn by the resin III are observed while the Ge can be quantitatively extracted (Fig. 6a and $\mathrm{b}$, distributions coefficients $\mathrm{Kd}$ are illustrated in Fig. SI-9 see supporting information). One limitation is when $\mathrm{Cu}$ is introduced as a competitive metal (Fig. 6c), indeed the extraction of the $\mathrm{Cu}$ increase significantly with the concentration of the resins. However it possible to selectively extract the $\mathrm{Ge}$ with respect to $\mathrm{Zn}$ and $\mathrm{Cu}$ with $\mathrm{SF} \mathrm{Ge} / \mathrm{Zn}>300$ and $\mathrm{SF} \mathrm{Ge/Cu}>10$ when a concentration of resin is $1 \mathrm{~g} / \mathrm{L}$. The preorganization of $\mathrm{OH}$ functions in the phenolic precursors was investigated with the implementation of resins based on phenol (VI) or a resorcinol (VII). The results (Table SI-2 see supporting information) indicate that the Ge is poorly extract around 7 and $16 \%$ for the phenol and resorcinol resin respectively with a $10 \mathrm{~g} / \mathrm{L}$ concentration of resin. 

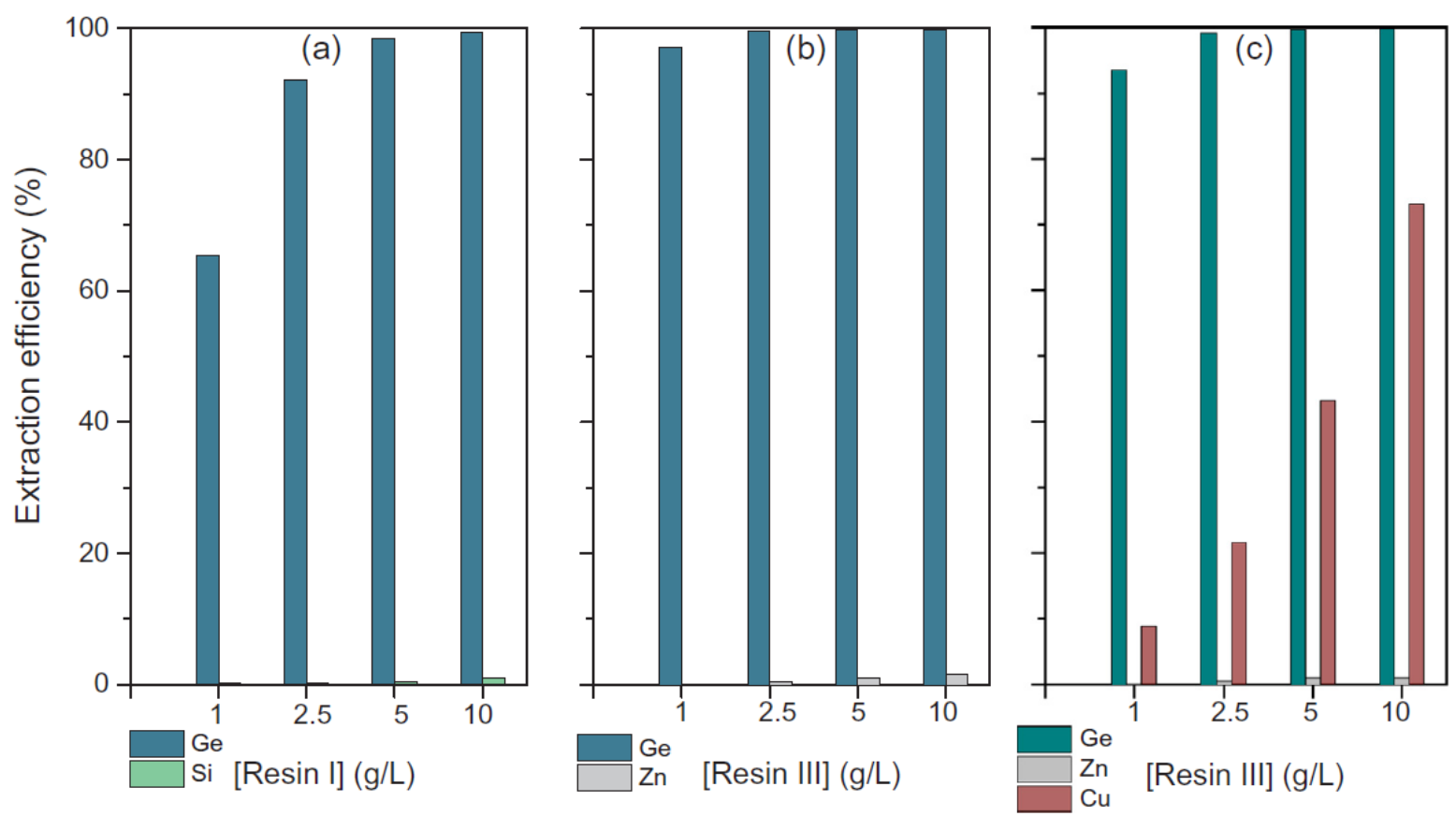

Fig. 6. Extraction efficiencies of cations by resin I and III at various concentration (1-10 g/L) from mixed cation solutions with

(a) Ge at $10 \mathrm{mg} / \mathrm{L}$ and Si $100 \mathrm{mg} / \mathrm{L}$ or (b) Ge at $10 \mathrm{mg} / \mathrm{L}$ and Zn $100 \mathrm{mg} / \mathrm{L}$ or (c) Ge at $10 \mathrm{mg} / \mathrm{L}, \mathrm{Zn} 100 \mathrm{mg} / \mathrm{L}$ and Cu $100 \mathrm{mg} / \mathrm{L}$ (pH=6).

It appear that the catechol (1,2-dihydroxybenzene) shows better performance than resorcinol (1,3dihydroxybenzene) and phenol (1-hydroxybenzene) suggesting an appropriate preorganization of the $\mathrm{OH}$ for the Ge extraction in the catechol.

Preliminary experiments have been performed to study the recuperation of germanium from the resin. After extraction, $25 \mathrm{mg}$ of resin I or resin III were contacted with $10 \mathrm{~mL}$ of a $1 \mathrm{M} \mathrm{HCl}$ solution to evaluate the stripping efficiency. It appear that in each case more than $80 \%$ of the germanium extracted by the resin can be stripped. The modifications of desorption conditions to obtain a complete stripping of the germanium could make it possible to envisage the resins reutilization.

\section{Conclusion}

The investigation on the behaviour of germanium extraction by phenolic polymers demonstrate that the resins with a catechol moiety are effective for the selective recovery of germanium. The selective sorption of germanium was studied in the presence of elements such as silicon, zinc or copper which are likely to be competitive cations in solutions from urban mines or mine deposits. The incorporation of 8-hydroxyquinoline in the catechol matrix produces changes in the selectivities properties of the resins. The selectivity $\mathrm{Ge} / \mathrm{Si}$ or $\mathrm{Ge} / \mathrm{Zn}$ is found to be influenced by the nature of the phenolic resins. Indeed, the catechol-formaldehyde resin shows the best performance for the separation of Ge towards Si with high separation factor while the catechol 8-hydroxyquinoline-based resins are not efficient for the Ge/Si separation but they show a selectivity between Ge and Zn. Preliminary experiments indicate that the recuperation of germanium is possible using an acidic eluting solution.

\section{Acknowledgments}

The authors acknowledge C. Rey, B. Baus Lagarde and P. Gaveau for their technical support regarding the TGA, ICP/AES and solid state NMR analyses. We gratefully acknowledge the financial support for this project provided by the Montpellier University and the Labex Project CheMISyst (ANR-10-LABX05-01). 


\section{Appendix A. Supplementary material}

Supplementary data associated with this article can be found, in the online version.

\section{References}

[1] R.R. Moskalyk, Miner. Eng. 17 (2004) 393-402.

[2] B. Depuydt, M. De Jonghe, W. De Baets, I. Romandic, A. Theuwis, C. Quaeyhaegens, C. Deguet, T. Akatsu, F. Letertre, Germanium-based Technologies, Elsevier, Oxford, 2007, pp. 1-39 ch. 1.

[3] G. Cote, D. Bauer, Hydrometallurgy 5 (1980) 149-160.

[4] A. de Schepper, Hydrometallurgy 1 (1976) 291-298.

[5] B. Gupta, N. Mudhar, Sep. Sci. Technol. 41 (2006) 549-572.

[6] S. Nusen, Z. Zhu, T. Chairuangsri, C.Y. Cheng, Hydrometallurgy 151 (2015) 122-132.

[7] A. Hernández-Expósito, J.M. Chimenos, A.I. Fernández, O. Font, X. Querol, P. Coca, F. García Peña, Chem. Eng. J. 118 (2006) 69-75.

[8] A.I. Zoumboulis, K.A. Matis, N.K. Lazaridis, Sep. Sci. Technol. 25 (1990) 463-476.

[9] S. Yasuda, K. Kawazu, Sep. Sci. Technol. 26 (1991) 1273-1277.

[10] Y. Inukai, Y. Kaida, S. Yasuda, Anal. Sci. 13 (1997) 339-344.

[11] Y. Inukai, T. Chinen, T. Matsuda, Y. Kaida, S. Yasuda, Analytica Chimica Acta 371 (1998) 187-193.

[12] P.J. Antikainen, Acta Chem. Scand. 13 (1959) 312-322.

[13] S. Virolainen, J. Heinonen, E. Paatero, Sep. Purif. Technol. 104 (2013) 193-199.

[14] A. Nozoe, M. Abe, K. Ohto, H. Kawakita, J. Chem. Technol. Biotechnol. 86 (2011) 1374-1378.

[15] A. Nozoe, K. Ohto, H. Kawakita, Sep. Sci. Technol. 47 (2012) 62-65.

[16] H. Takemura, S. Morisada, K. Ohto, H. Kawakita, Y. Matsuo, D. Fukuda, J. Chem. Technol. Biotechnol. 88 (2013) 1468-1472.

[17] F. Arroyo Torralvo, C. Fernández-Pereira, M.C. Campanario, Ind. Eng. Chem. Res. 49 (2010) 48174823.

[18] F. Arroyo, C. Fernández-Pereira, J. Olivares, P. Coca, Ind. Eng. Chem. Res. 48 (2009) 3573-3579.

[19] F. Arroyo Torralvo, C. Fernández-Pereira, Miner. Eng. 24 (2011) 35-41.

[20] G.S. Pokrovski, J. Schott, Geochimica et Cosmochimica Acta 62 (1998) 3413-3428.

[21] G.S. Pokrovski, F. Martin, J.-L. Hazemann, J. Schott, Chem. Geol. 163 (2000) 151-165.

[22] J.R. Parrish, Chem. Industry (1955) 386-387.

[23] L.D. Pennington, M.B. Williams, Ind. Eng. Chem. 51 (1959) 759-762.

[24] M.V. Tarase, A.B. Zade, W.B. Gurnule, J. Appl. Polym. Sci. 108 (2008) 738-746.

[25] R.S. Azarudeen, M.A.R. Ahamed, A.R. Burkanudeen, Desalination 268 (2011) 90-96.

[26] R.S. Azarudeen, R. Subha, D. Jeyakumar, A.R. Burkanudeen, Sep. Purif. Technol. 116 (2013) 366377.

[27] K.A.K. Ebraheem, M.S. Mubarak, Z.J. Yassien, F. Khalili, Sep. Sci. Technol. 35 (2000) 2115-2125.

[28] M. Draye, K.R. Czerwinski, A. Favre-Reguillon, J. Foos, A. Guy, M. Lemaire, Sep. Sci. Technol. 35 (2000) 1117-1132.

[29] F. Al-Rimawi, A. Ahmad, F.I. Khalili, M.S. Mubarak, Solvent Extr. Ion Exch. 22 (2004) 721-735.

[30] R. Ameta, V. Patel, J. Joshi, Iran. Polym. J. 16 (2007) 615-625.

[31] M. Kapadia, M. Patel, G. Patel, J. Joshi, J. Polym. Res. 15 (2008) 285-293.

[32] A. Favre-Reguillon, B. Dunjic, M. Lemaire, R. Chomel, Solvent Extr. Ion Exch. 19 (2001) 181-191.

[33] D. Banerjee, M.A. Rao, P.K. Wattal, Sep. Sci. Technol. 48 (2013) 133-139.

[34] S.I. Kargov, L.A. Shelkovnikova, V.A. Ivanov, Russ. J. Phys. Chem. A 86 (2012) 860-866.

[35] G. Arrachart, A. Kenaan, S. Gracia, R. Turgis, V. Dubois, S. Pellet-Rostaing, Sep. Sci. Technol. 50 (2015) 1882-1889.

[36] M. Palamarchuk, A. Egorin, E. Tokar, M. Tutov, D. Marinin, V. Avramenko, J. Hazard. Mater. 321 (2017) 326-334.

[37] S.K. Samanta, M. Ramaswamy, B.M. Misra, Sep. Sci. Technol. 27 (1992) 255-267.

[38] N. Dumont, A. FavreReguillon, B. Dunjic, M. Lemaire, Sep. Sci. Technol. 31 (1996) 1001-1010. 